\title{
Development of an Effective System for Selecting Construction Materials for Sustainable Residential Housing in Western Australia
}

\author{
Muhammad Rashid Minhas, Vidyasagar Potdar \\ School of Management, Curtin University, Perth, Australia \\ Email:muhammad.minhas@postgrad.curtin.edu.au,v.potdar@curtin.edu.au
}

How to cite this paper: Minhas, M.R. and Potdar, V. (2020) Development of an Effective System for Selecting Construction Materials for Sustainable Residential Housing in Western Australia. Applied Mathematics, 11, 825-844.

https://doi.org/10.4236/am.2020.118054

Received: July 19, 2020

Accepted: August 28, 2020

Published: August 31, 2020

Copyright $\odot 2020$ by author(s) and Scientific Research Publishing Inc. This work is licensed under the Creative Commons Attribution International License (CC BY 4.0).

http://creativecommons.org/licenses/by/4.0/

\begin{abstract}
Urbanization and living comfort have revolutionized the construction industry. Many techniques and strategies have been used to improve the overall efficiency of construction and to reduce waste during and after the construction activity; some are cost effective and some not. Sustainable construction strategies have addressed these issues by proposing relatively more cost effective and environment-saving solutions. One strategy is to select sustainable construction materials at the building design stage. This article involved a questionnaire survey to collect data about local technical stakeholders' (architects, designers, engineers, estimators, and managers) awareness of environmental sustainability and current practices for selecting construction materials. A sustainability index (SI) was developed using SPSS (Statistical Package for the Social Sciences) for the complex statistical analysis. These data were used to develop a decision support system (DSS) using the multi-criteria decision making (MCDM) technique, the TOPSIS. The support system was validated by applying it to sustainable roof products in a pilot case study-these materials are frequently used in local markets for residential construction in West Australia. So the main objective was to get insight to local market trends and features involved in construction materials selection. Data analysis was carried out to develop a decision support system to help technical stakeholders in construction materials selection process.
\end{abstract}

\section{Keywords}

Construction Industry, Sustainability Index (SI), Multi-Criteria Decision Making (MCDM), Decision Support System (DSS), TOPSIS 


\section{Introduction}

In the past the global construction industry has developed rapidly in terms of advanced technology and the incorporation of safety and sustainability. Similarly, the Australian construction industry now considers sustainability as a vital factor for maintaining a balance in preservation and consumption of natural resources. To investigate the local trends and general procedures in the selection process for materials in residential building construction, a questionnaire survey was developed and circulated among the leading construction companies in Western Australia.

Survey response rate and validity: Data were collected in three survey formats: postal, online, and self-administered surveys. A total number of 52 survey questionnaires were sent to construction companies with a cover letter and a form for participant consent. From these, 11 responses were received (response rate $=21.15 \%$; Figure 1 ). This response rate was considered adequate because other researchers in the construction industry also reported response rates for postal surveys between $20 \%$ and $30 \%$ [1] [2] [3].

For the online surveys, 35 company representatives were sent a uniform resource locator (URL) link to access the survey and record their responses. The response rate was $48.57 \%$ (17 responses). Face-to-face, self-administered surveys were also conducted with 7 company representatives ( 23 companies sent request; $30.43 \%$ response rate). This method of data collection is considered the best; complete responses are received through this method. All survey responses were evaluated before analysis to verify that all questions were answered; missing values were adjusted in the analysis with SPSS (Statistical Package for the Social Sciences, (version 24)). Some irrational responses and suggestions were received but most responses were relevant based upon the work experience of the respondents.

We used a Likert scale in our survey, which is considered reliable to investigate the overall perceptions and experiences of a group of relatively homogeneous

\section{Survey Response Rate}

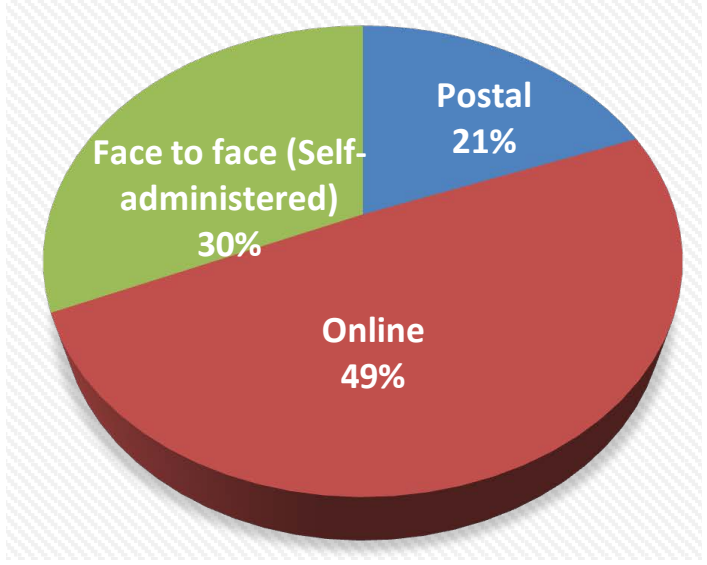

Figure 1. Survey response rate. 
individuals of similar backgrounds and trades [4]. Using a multi-criteria decision making (MCDM) technique, we processed the data to develop a sustainability index (SI) for ranking the most appropriate and sustainable building construction materials. The system was validated by running a pilot analysis on local sustainable roofing materials from two major material suppliers.

Margin of error: For an inferential statistical analysis, researchers agree a sample size ( $n)$ of more than 30 is required to obtain an accurate value [5] [6] [7] [8]. Prior research validated that minimum threshold value to rank a data acceptable is 30 . We got the response from more than 30 construction firms, hence our sample size $(n=36)$ is acceptable for statistical analysis with the appropriate analysis tool to get acceptable and reliable results.

\section{Statistical Data Analysis}

SPSS (Statistical Package for the Social Sciences, version 24) was used to analyze the data. Frequencies, percentages, averages were calculated. All values are used for open-ended questions. Data were collected on the organization profiles (i.e. type, size, and age of organization; area of building projects, focus, and main client type) to obtain overall snapshots of the organizations.

\subsection{Level of Awareness of Environmental Issues}

All company representatives and technical stakeholders were somewhat aware of environmental parameters, but only $33.34 \%$ of the 36 were extremely aware. Almost $20 \%$ were only slightly aware; most of these respondents had a trade background, with no higher education degree in construction (Table 1).

\section{Considering environmental issues at the conceptual design stage}

A large body of literature describes the importance of addressing environmental issues at the first step in the construction process, the conceptual design stage [9] [10]. To investigate the degree of agreement or disagreement regarding this practice, respondents were asked "Is it important to consider the environmental issues at the conceptual stages?" A seven-point Likert scale recorded their viewpoint ( 1 = Strongly disagree, 7 = Strongly agree); the extended Likert scale was used to canvass the full spectrum of opinions and current general practice in the local market (Table 2).

Table 1. Level of awareness of environmental issues in building construction.

\begin{tabular}{cccc}
\hline Awareness scale & Frequency & Percent & Cumulative percent \\
\hline Extremely aware & 12 & 33.34 & 33.34 \\
Moderately aware & 8 & 22.23 & 55.57 \\
Somewhat aware & 9 & 25.0 & 80.57 \\
Slightly aware & 7 & 19.45 & 100.0 \\
Total & & 100.0 & \\
\hline
\end{tabular}

Source: Analysis of survey data (2018). 
Table 2. Consideration of environmental issues at conceptual design stage.

\begin{tabular}{cccc}
\hline Agreement scale & Frequency & Percent & Cumulative percent \\
\hline Strongly disagree & 0 & 0 & 0 \\
Disagree & 0 & 0 & 0 \\
Somewhat disagree & 0 & 0 & 0 \\
Neutral & 3 & 8.33 & 8.33 \\
Somewhat agree & 6 & 16.66 & 24.99 \\
Agree & 15 & 41.66 & 66.65 \\
Strongly agree & 12 & 33.33 & 100 \\
Total & & 100 & \\
\hline
\end{tabular}

Source: Analysis of survey data (2018).

Table 2 shows that most (about 75\%) of the respondents (75\%) agreed or strongly agreed that the best time to consider environmental or and sustainability issues is at the conceptual stage. Other researchers report similar findings as well [11]. Considering all these environmental and sustainability issues at the start of the process allows us to change our design accordingly, and the capital cost can be well managed and minimized.

\subsection{Building Design Priorities}

The analysis showed that the decision makers were aware of the importance of using environmentally friendly and sustainable construction materials. The respondents were asked to prioritize their objectives to gauge the level of importance they assigned to project objectives, including environmental impacts and sustainable construction materials (Table 3 ).

The following formula was used to calculate the values in Table 3:

$$
\mathrm{RI}=\sum \frac{w}{A \times N}
$$

where $\mathrm{RI}=$ relative index, $w=$ weighting given by respondents (range $1-7$ ), $A=$ highest weight (i.e. 7), $N=$ total number of respondents. The value of the relative index ranges from 0 to 1 .

The respondents' highest priority was to satisfy the client's specifications (Table 3), which indicates that most of the time efforts are made to reduce the cost as well.

\section{Sustainability Considerations}

The implementation of sustainability depends upon the knowledge and awareness of technical stakeholders (e.g. architects, designers, engineers, estimators, and managers).

Although the respondents stated they were aware of sustainability and its importance in construction, $52.77 \%$ had only an average knowledge of the sustainable products available in the market. Moreover, the proportion of respondents 
Table 3. Ranking of project objectives.

\begin{tabular}{ccccc}
\hline Project Objective & Weighted total & RI & Rank & Mean Value \\
\hline Satisfy Client Specifications & 140 & 0.778 & 1 & 3.889 \\
Meet Project Deadline & 134 & 0.744 & 2 & 3.722 \\
Meet Building Regulation & 134 & 0.744 & 3 & 3.722 \\
Sustainability Criteria & 130 & 0.722 & 4 & 3.611 \\
Environmental Impacts & 126 & 0.700 & 5 & 3.500 \\
Minimize the Cost & 125 & 0.694 & 6 & 3.472 \\
\hline
\end{tabular}

Source: Analysis of survey data 2018.

with poor knowledge (22.22\%) exceeded the proportion with good knowledge (16.66\%) (Table 4). Hence, the major stakeholders need to learn about sustainable products and their efficacy and adaptability. Most respondents thought that clients or their representatives are less concerned about this factor than about other considerations, and so they pay less attention to this issue. The small percentage of respondents with excellent knowledge (8.33\%) all belonged to well-established, large organizations.

\subsection{Sustainability Assessment}

In contrast, most respondents (88.88\%) agreed that it is important to select sustainable materials for building construction (Table 5); only one respondent (2.77\%) provided any reasons for not doing so (cost and lack of skilled labor).

Despite the respondents' prior claim of knowing about sustainability and its importance, the analysis showed that the percentage of their projects in which sustainability was considered important was low (Table 6).

A majority of respondents (36\%) completed projects without considering sustainability as an important factor for building construction, although implementing sustainability activities can give competitive advantage over rival firms that are reluctant to implement those activities [12].

\subsection{Constraints in Selecting Sustainable Materials}

The building industry uses large quantities of raw materials and energy in all stages from construction to operation. This means choosing materials with high content in embodied energy involve in high energy demand at construction stage and vice versa in operational phase [13] [14].

To gauge the real-world problems or obstacles faced by the technical stakeholders in selecting sustainable materials, respondents were asked to rank such issues on a 5-point Likert scale (1, low, 5, high). The degree of agreement, calculated as Kendall's W, was 0.248 (Table 7). This value indicates that almost all of the technical stakeholders face the same obstacles, with some exceptions.

The degree of agreement is calculated Kendall's $W=0.248$ which shows almost all technical stakeholders are facing the same obstacles with some exceptions. 
Table 4. Knowledge of sustainable design.

\begin{tabular}{ccccc}
\hline Knowledge Scale & Frequency & Percent & Valid Percent & Cumulative Percent \\
\hline Excellent & 3 & 8.33 & 8.33 & 8.33 \\
Good & 6 & 16.66 & 16.66 & 25 \\
Average & 19 & 52.77 & 52.77 & 77.76 \\
Poor & 8 & 22.22 & 22.22 & 100 \\
Total & & 100 & 100 & \\
\hline
\end{tabular}

Source: Analysis of survey data 2018.

Table 5. Importance of sustainable materials in building development.

\begin{tabular}{ccccc}
\hline Knowledge scale & Frequency & Percent & Valid Percent & Cumulative percent \\
\hline Yes & 32 & 88.88 & 88.88 & 88.88 \\
No & 3 & 8.33 & 8.33 & 97.21 \\
If no, give reason & 1 & 2.77 & 2.77 & 100 \\
Total & & 100 & 100 & \\
\hline
\end{tabular}

Source: Analysis of survey data (2018).

Table 6. Projects considering sustainability important.

\begin{tabular}{cccc}
\hline Projects & Frequency & Percent & Cumulative Percent \\
\hline$<10 \%$ & 13 & 36.11 & 36.11 \\
$10 \%-20 \%$ & 10 & 27.77 & 63.88 \\
$21 \%-30 \%$ & 5 & 13.88 & 77.76 \\
$31 \%-40 \%$ & 2 & 5.55 & 83.31 \\
$41 \%-50 \%$ & 4 & 11.11 & 94.42 \\
$>50 \%$ & 2 & 5.55 & 100 \\
Total & & 100 & \\
\hline
\end{tabular}

Source: Analysis of survey data (2018).

Table 7. Constraints in sustainable material selection.

\begin{tabular}{ccc}
\hline Stakeholder influence & $\mathrm{RI}^{\mathrm{a}}$ & Rank \\
\hline Lack of information & 0.73 & 2 \\
Uncertainty in liability of work & 0.67 & 7 \\
Maintenance concern & 0.73 & 3 \\
Building code regulations & 0.65 & 6 \\
Lack of tools and data & 0.70 & 5 \\
Perception of extra cost being incurred & 0.76 & 1 \\
Perception of extra time being incurred & 0.72 & 11 \\
Perception that sustainable materials are low in quality & 0.45 & 10 \\
Aesthetically less pleasing & 0.55 & \\
\hline
\end{tabular}




\begin{tabular}{ccc}
\hline Project will be delayed & 0.67 & 9 \\
Limited suppliers & 0.68 & 6 \\
Low flexibility in alternatives & 0.65 & 5 \\
Unwilling to adopt the change & 0.66 & 6 \\
Kendall's W & & $(0.248)$ \\
\hline
\end{tabular}

a Relative index. Source: Analysis of survey data (2018).

\section{Development of Criteria for Sustainable Material Selection}

The gap between information and implementation can be reduced by developing systems and IT features that are easy to use. This is a combined responsibility of all sectors involved in the construction industry. It is a mutual responsibility of government and the private sector to introduce and implement regulations for a "greener" and safer environment for future generations (Raynsford, 2000).

The criteria for sustainable material selection that were investigated were divided into three categories: environmental criteria, socio-economic criteria, and technical criteria (Table 8).

The respondents were asked to rank the sub-criteria for importance and the data were analyzed (Table 9).

Aesthetics was ranked first in the socio-economic category $(\mathrm{RI}=0.88$; Table 9). This criterion was designated as high importance as per our predefined values: all factors with an RI $>0.8$ were considered of high importance and those with an $\mathrm{RI}<0.8$ considered of medium to high importance.

A decision model will help technical stakeholders to select from a wide range of options, either classical or innovative. We used the above sustainability criteria for computational analysis in order to formulate the best combination of alternative construction materials. Six major criteria were used (Figure 2). These 6 criteria were further divided into 23 sub-criteria (Table 10).

\section{TOPSIS-Based Approach for Prioritized Aggregation}

An aggregated MCDM environment means combining the values of a set of attributes to represent a single value for the entire set of attributes. Much work has been done to introduce the prioritization in aggregation method using the TOPSIS. The derivation of our MCDM model using this prioritization approach is described below.

A sustainability index framework basically helps the decision makers to integrate the issues of sustainability while selecting the available construction materials. Selecting sustainable construction materials from the pool of alternative sustainable materials is a time consuming and difficult practice. Applying the MCDM technique is the best method for integrating objective and subjective weights of various conflicting criteria in order to choose the most appropriate sustainable material. However, the process is challenging. 
Table 8. Criteria for sustainable material selection for construction professionals.

\begin{tabular}{|c|c|c|}
\hline Environmental criteria & Socio-economic criteria & Technical criteria \\
\hline E1: Potential for reuse & S1: Disposal cost & T1: Maintainability \\
\hline $\begin{array}{l}\text { E2: Environmentally favorable disposal } \\
\text { options }\end{array}$ & S2: Health and safety & T2: Buildability \\
\hline E3: Air quality impacts & S3: Maintenance cost & T3: Resistance to decay \\
\hline E4: Ozone depletion potential & S4: Aesthetics & T4: Fire resistance \\
\hline $\begin{array}{l}\text { E5: Environmental impact during } \\
\text { manufacturing }\end{array}$ & S5: Use of local materials & T5: Life expectancy \\
\hline E6: Less toxicity & S6: Capital cost & T6: Energy saving \\
\hline E7: Regulatory compliance & S7: Skilled labor availability & \\
\hline \multicolumn{3}{|l|}{ E8: Reduce pollution } \\
\hline \multicolumn{3}{|l|}{ E9: Wastage in production } \\
\hline E10: Raw materials extraction process & & \\
\hline
\end{tabular}

Source: Analysis of survey data (2018).

Table 9. Ranking of criteria for sustainable material selection for construction professionals.

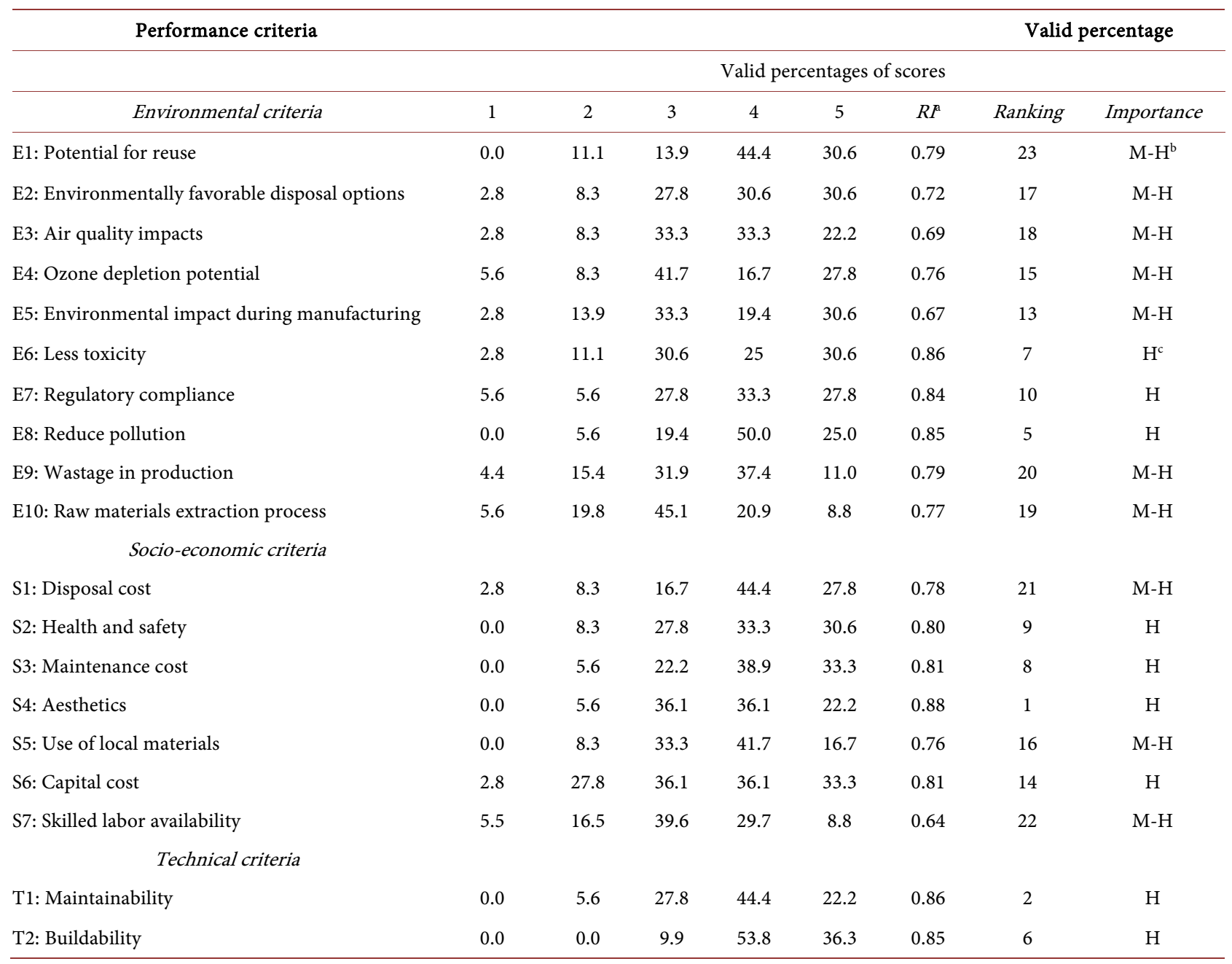




\section{Continued}

\begin{tabular}{lcccccccccc}
\hline T3: Resistance to decay & 0.0 & 8.3 & 27.8 & 30.6 & 33.3 & 0.79 & 4 & M-H \\
T4: Fire resistance & 0.0 & 8.3 & 27.8 & 30.6 & 33.3 & 0.84 & 11 & H \\
T5: Life expectancy & 0.0 & 5.6 & 25.0 & 30.6 & 38.9 & 0.78 & 12 & M-H \\
T6: Energy saving & 0.0 & 2.8 & 38.9 & 30.6 & 27.8 & 0.84 & 3 & H \\
\hline
\end{tabular}

${ }^{a}$ Relative index. ${ }^{b}$ medium to high. chigh. Source: Analysis of survey data (2018).

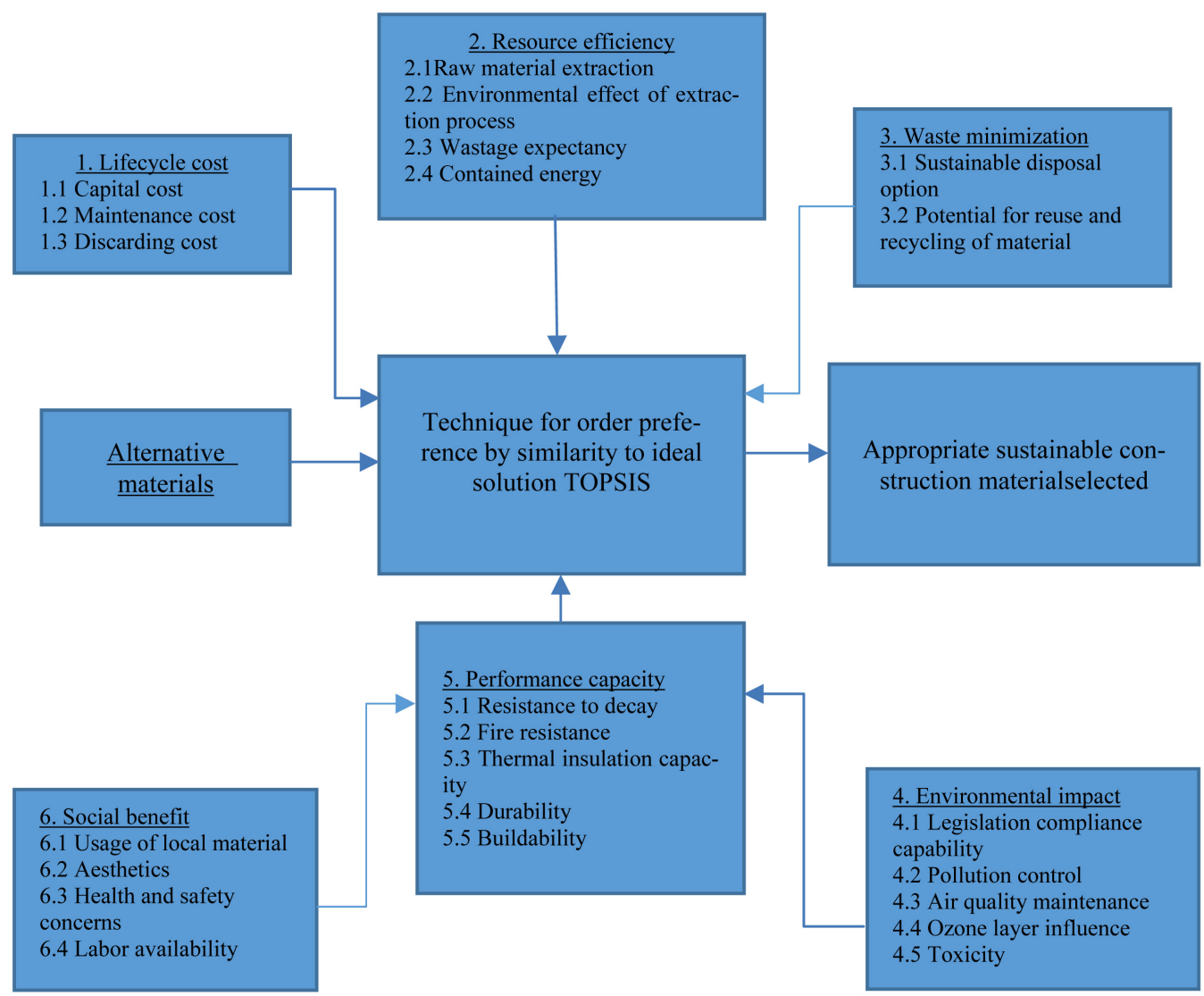

Figure 2. Conceptual framework for sustainable material selection.

The first step is to determine the most suitable aggregation method, usually from two major types: the crisp aggregation method, which is used to aggregate the real values; and the fuzzy aggregation method, which is used to aggregate the linguistic labels [15].

The second, most complicated, step is to define the boundary condition. The boundary condition compels the result of an aggregation function $f(x)$. The limit is defined as the minimal and maximal boundaries of possible output.

$$
f(0, \cdots, 0)=0 \text { and } f(1, \cdots, 1)=1 \text {, where } x \in[0,1]
$$

The commutativity property states that ordering/ranking of arguments does not matter when there is equal importance or no relationship is considered among the different criteria.

$$
f\left(x_{1}, x_{2}, \cdots, x_{n}\right)=f\left(x_{2}, x_{1}, \cdots, x_{n}\right)=f\left(x_{n}, x_{2}, x_{1}, \cdots\right), \quad x \in S
$$


Table 10. Criteria and sub-criteria grouped with type.

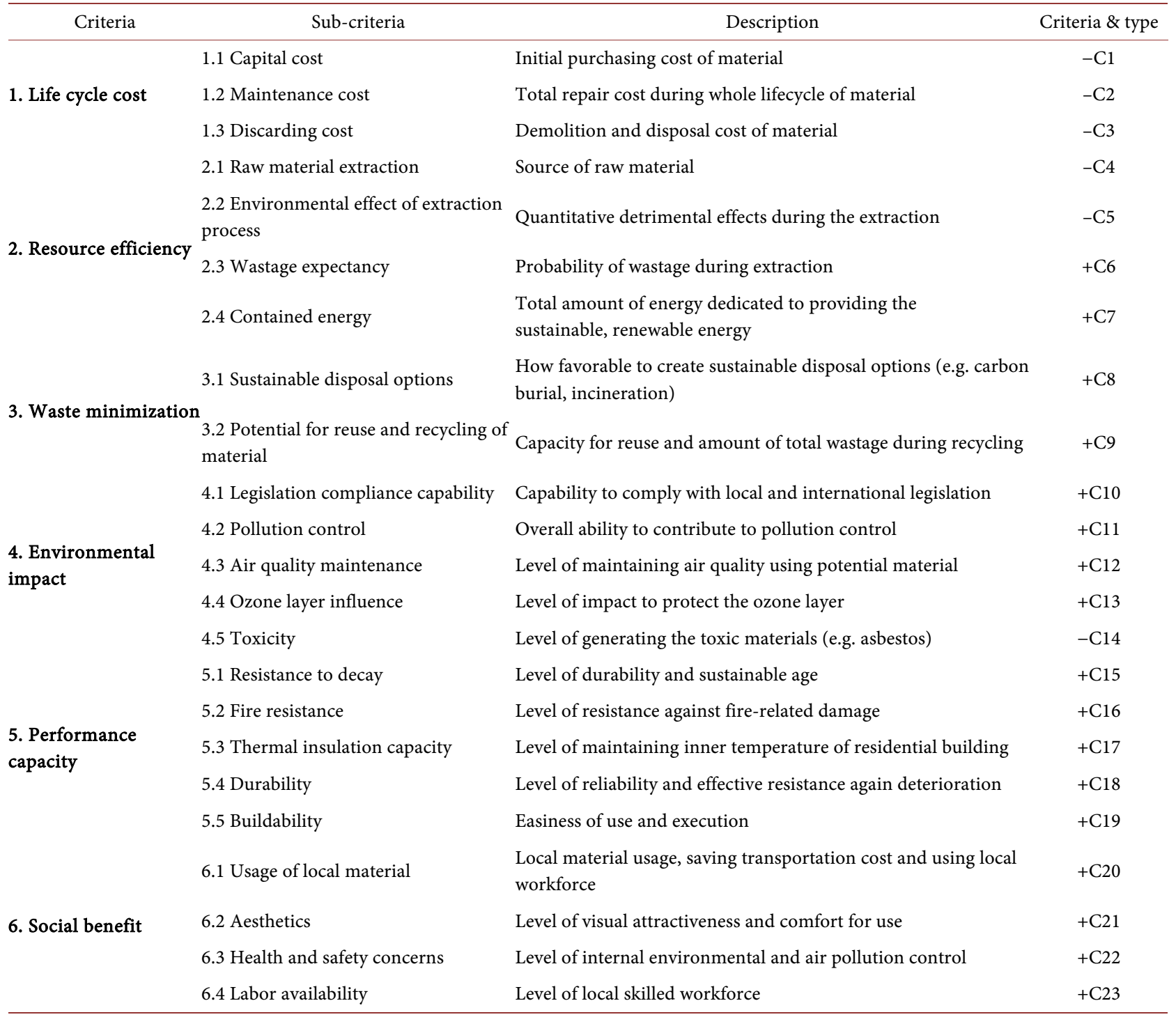

The continuity condition means that the aggregation function does not change markedly' if small changes were made to the attributes considered in the aggregation process.

$\mathrm{U}_{x \in S}[0,1]^{x} \rightarrow[0,1]$ is a continuous aggregation function if:

$$
f(x):[0,1]^{x} \rightarrow[0,1]
$$

The monotonicity condition implies that aggregation functions are monotonic, that is, the aggregation function shows a "non-decreasing" relationship between the criteria and the aggregation maneuvers.

$$
x_{i}^{\prime}>x_{i} \text {, then } f\left(x_{i}^{\prime}\right)>f\left(x_{i}\right) \text { where } x \in S
$$

The idem-potencies condition is an algebraic property that belongs to the binary operation and displays the relationship if:

$$
f(x, x, \cdots, x)=x \text { where } x \in S
$$


The associativity condition is the ability of the aggregation function to retaliate against the choice of group, which should not influence the overall result of the aggregation process.

$$
f\left(f\left(x_{1}, x_{2}, \cdots\right), x_{n}\right)=f\left(f\left(x_{1}, x_{2}\right), \cdots, x_{n}\right), x \in S \quad[16]
$$

Many applications require the evaluation of a set of criteria with prioritized relationships within the set in order to reach a conclusion. [17] [18] [19].

The TOPSIS is an approach that originates from the geometric concept of displaced ideal point, which means that the criterion under investigation must be situated between the positive (most favorable) and negative (least favorable) locations [20].

Determining the weights and criteria ranking: Previous studies have discussed many methods for criteria ranking and weight determination [21] [22] [23]. There are two primary methods. The "direct choice of weights" method directly assigns weights based on the opinions and consensus of a group of experts. The "weights determination from data" method derives the weights of criteria from the data available in the same domain for aggregation purposes. We used the first method to get our weighted data set.

\section{Application and Validation of Sustainability Model}

Considering the complexity of the data-collection process and the research output, we conducted an empirical inquiry using a real-world, practical scenario. We collected data on roofing materials that are specifically used in residential buildings in Western Australia and are available from the two major suppliers of roofing tiles.

This validation involved the application and evaluation of two suppliers with six tile options. This hypothetical case study was based on the roofing tiles from different suppliers and different options depending on the type of material selected for the test run and the type of structure implemented. Cost was one of the factors considered; however, the most important factors were the six main criteria and related sub-criteria (see Table 10). The details and physical characteristics of the materials are presented in Table 11.

This model analyzes and ranks the sustainable options by using mathematical

Table 11. Roofing tile options.

\begin{tabular}{|c|c|c|c|c|c|}
\hline & Roof type & Building & Structural location & Roof tile size & Roof pitch \\
\hline $\begin{array}{l}\text { Option 1: } \\
\text { two alternatives, from } \\
\text { two different suppliers }\end{array}$ & $\begin{array}{l}\text { Timber truss } \\
\text { pitched roof }\end{array}$ & Residential & $\begin{array}{l}\text { Treated timber trussed roof with anti-con underlay, } \\
\text { batts insulation, \& concrete interlocking tiles }\end{array}$ & $418 \mathrm{~mm} \times 260 \mathrm{~mm}$ & 18 - 20 degrees \\
\hline $\begin{array}{l}\text { Option 2: } \\
\text { two alternatives, from } \\
\text { two different suppliers }\end{array}$ & $\begin{array}{l}\text { Timber truss } \\
\text { pitched roof }\end{array}$ & Residential & $\begin{array}{l}\text { Treated timber trussed roof with anti-con underlay, } \\
\text { batts insulation, \& clay terracotta tiles }\end{array}$ & $418 \mathrm{~mm} \times 260 \mathrm{~mm}$ & 18 - 20 degrees \\
\hline $\begin{array}{l}\text { Option 3: } \\
\text { two alternatives, from } \\
\text { two different suppliers }\end{array}$ & $\begin{array}{l}\text { Timber truss } \\
\text { pitched roof }\end{array}$ & Residential & $\begin{array}{l}\text { Structurally insulated roofing panels with anti-con } \\
\text { underlay \& designer ceramic tiles }\end{array}$ & $418 \mathrm{~mm} \times 260 \mathrm{~mm}$ & 18 - 20 degrees \\
\hline
\end{tabular}


implications with the MCDM technique. The data for this pilot study were collected as part of the survey questionnaire. The experts ranked the different alternatives from the suppliers based on the criteria and sub-criteria provided to them. These values were tabulated in an MS Excel ${ }^{\mathrm{TM}}$ spreadsheet and analyzed by running the TOPSIS model. The main factors that drive the selection of roofing materials are:

1) Compliance with Australian building codes and local estate building codes.

2) House type, orientation, and building construction.

3) Local council requirements.

4) Energy management, insulation selection, and the overall anatomy of the building roof.

Roof types have different pitch values depending on building type and house style. The most common pitches for roofing in Australia are 18 - 20 degrees, depending on the materials used. The prime reason for selecting roofing material for the case study is that it can be tailored at the design stage and plays an important role in maintaining the overall sustainability ranking of building.

The three options in Table 11 were tested against six alternatives from the two major suppliers in the Australian construction industry. The alternatives have various competitive advantages over each other.

The tabulated values in the Excel spreadsheet assigned the sub-criteria with positive or negative signs: criteria with an inverse relationship to sustainability are marked as negative and criteria that enhance the sustainability are marked as positive. The six alternatives were tested against the 23 sub-criteria related to those main six. The MCDM technique with TOPSIS gives a final ranking of these criteria and sub-criteria based on expert opinion [24].

Yoon and Hwang introduced the TOPSIS method, which proposes that the best alternative has the shortest distance to the ideal solution [25] [26]. The attribute which favors an alternative material is called the best attribute and the other is called the worst attribute. The goal of this approach is to find the Euclidean space from the ideal solution [27]. TOPSIS comprises six major steps, which are described as follows using our hypothetical problem of roofing material (roof tiles) from the two major suppliers of roof tiling.

Step 1: Calculate the normalized matrix.

The normalization is calculated using Equation (7) [28]:

$$
\overline{X_{i j}}=X_{i j} / \sqrt{\sum_{j=1}^{n} X_{i j}^{2}} \text { where } i=1,2, \cdots, n \text { and } j=1,2, \cdots, m
$$

In a matrix, the $i$ and $j$ belong to the first row and first column value.

Step 2: Calculate the weighted normalized matrix.

The normalized matrix is then multiplied with the weighted value as per equation (8);

$$
V_{i j}=\overline{X_{i j}} \times W_{j} \text { [27] [29] }
$$

Step 3: Calculate the ideal best and ideal worst value.

In this step, the ideal best value is the value which suits the criteria, represented by the maximum value; the ideal best negative value which opposes the agree- 
ment of criteria is represented by the minimum value.

Step 4: Calculate the Euclidean distance from ideal best value.

This distance will be the closest value to ideal best value, using the Equation (9):

$$
S_{i}^{+}=\left[\sum_{j=1}^{n}\left(V_{i j}-V_{J^{+}}\right)^{2}\right]^{0.5}
$$

Step 5: Calculate the Euclidean distance from ideal worst value.

This distance will be the closest value to ideal worst value, using Equation (10):

$$
S^{-}{ }_{i}=\left[\sum_{j=1}^{n}\left(V_{i j}-V_{J^{-}}\right)^{2}\right]^{0.5}[30]
$$

Step 6: Calculate the relative closeness to the ideal solution.

The relative closeness to the ideal solution is calculated using Equation (11):

$$
C_{\mathrm{i}}=S^{-}{ }_{\mathrm{i}} / S_{\mathrm{i}}^{+}+S_{\mathrm{i}}^{-}
$$

The final calculated values rank the alternatives, with 1 being the best alternative (Table 12). The MCDM can be used to solve the problem of material selection where an infinite number of alternatives exist.

\begin{tabular}{|c|c|}
\hline \multicolumn{2}{|r|}{ Ranked list of criteria } \\
\hline $\mathrm{C} 1$ & Capital cost \\
\hline $\mathrm{C} 2$ & Maintenance cost \\
\hline $\mathrm{C} 3$ & Discarding cost \\
\hline $\mathrm{C} 4$ & Raw material extraction \\
\hline C5 & Environmental effect of extraction process \\
\hline C6 & Wastage expectancy \\
\hline $\mathrm{C} 7$ & Contained energy \\
\hline $\mathrm{C} 8$ & Sustainable disposal option \\
\hline C9 & Potential for reuse and recycling of material \\
\hline $\mathrm{C} 10$ & Legislation compliance capability \\
\hline $\mathrm{C} 11$ & Pollution control \\
\hline $\mathrm{C} 12$ & Air quality maintenance \\
\hline $\mathrm{C} 13$ & Ozone layer influence \\
\hline $\mathrm{C} 14$ & Toxicity \\
\hline C15 & Resistance to decay \\
\hline $\mathrm{C} 16$ & Fire resistance \\
\hline $\mathrm{C} 17$ & Thermal insulation capacity \\
\hline $\mathrm{C} 18$ & Durability \\
\hline C19 & Buildability \\
\hline $\mathrm{C} 20$ & Usage of local material \\
\hline $\mathrm{C} 21$ & Aesthetics \\
\hline $\mathrm{C} 22$ & Health and safety concerns \\
\hline $\mathrm{C} 23$ & Labor availability \\
\hline
\end{tabular}

Tables 13-17 show the calculations in the Excel spreadsheet. The weighted Table 12. Ranked list of criteria. 


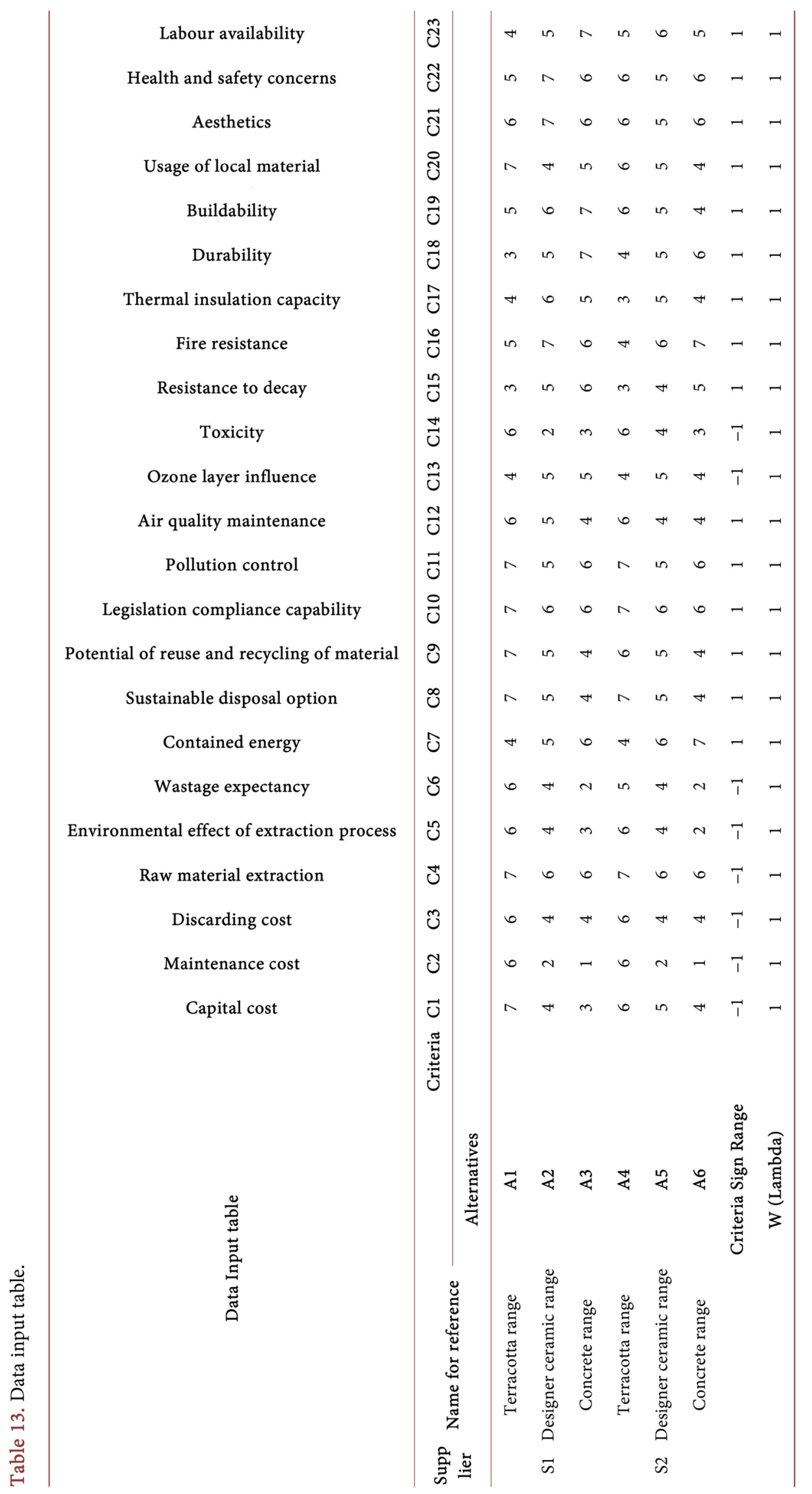




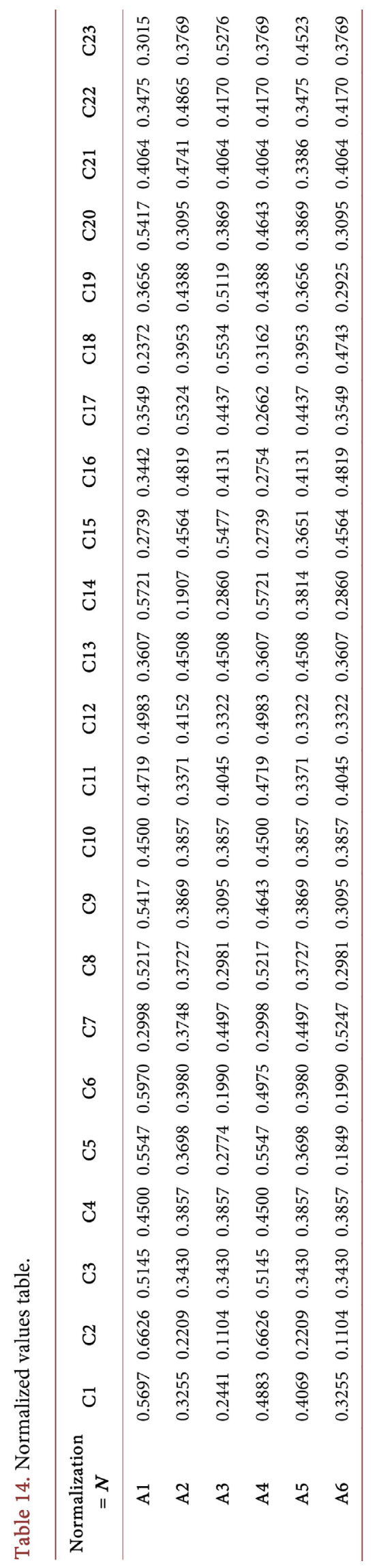




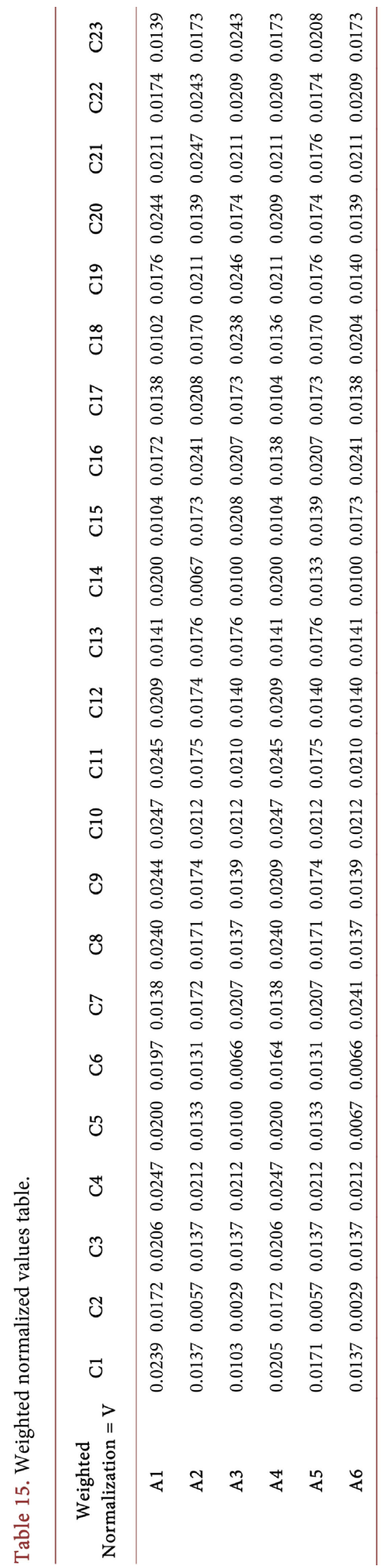




\begin{tabular}{|c|c|c|}
\hline & శึ & 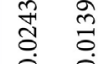 \\
\hline & กิ & 产 \\
\hline & $\vec{N}$ & 学 \\
\hline & & $\exists \quad a$ \\
\hline & ปิ & 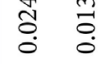 \\
\hline & 9 & 惫 恋 \\
\hline & & $\begin{array}{cc}0 & 0 \\
\infty & 1\end{array}$ \\
\hline & $\stackrel{\infty}{u}$ & $\begin{array}{ll}\text { } & 0 \\
0 & 0 \\
0\end{array}$ \\
\hline & $\vec{y}$ & 灾 \\
\hline & & $=\infty$ \\
\hline & $\stackrel{0}{0}$ & $\begin{array}{ll}\vec{d} \\
\stackrel{d}{0}\end{array}$ \\
\hline & $n$ & 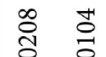 \\
\hline & & \\
\hline & $\vec{U}$ & 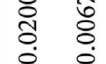 \\
\hline & $m$ & $\stackrel{\Xi}{\cong}$ \\
\hline & & \\
\hline & $\tilde{U}$ & 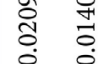 \\
\hline & $=$ & 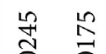 \\
\hline & 0 & $\ddot{0}$ \\
\hline & $\stackrel{\circ}{U}$ & 䜦 \\
\hline & & अ \\
\hline & 8 & $\stackrel{a}{0}$ \\
\hline & $\stackrel{\infty}{0}$ & 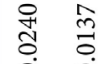 \\
\hline & & $F \stackrel{\infty}{\mp}$ \\
\hline & 0 & 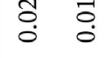 \\
\hline & ن & $\begin{array}{ll}5 & 0 \\
0 & 0\end{array}$ \\
\hline & 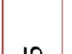 & 80 \\
\hline $\begin{array}{l}\text { है } \\
\text { है }\end{array}$ & 0 & $\begin{array}{ll}\text { ¿ै } \\
0\end{array}$ \\
\hline $\begin{array}{l}3 \\
0\end{array}$ & $\ddot{J}$ & $\begin{array}{ll}\text { If } \\
\text { तु } \\
0 \\
0\end{array}$ \\
\hline 苛 & 3 & 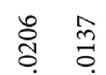 \\
\hline $\overrightarrow{\widetilde{\sigma}}$ & & 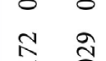 \\
\hline 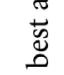 & ป & $\begin{array}{ll}0 \\
0 \\
0\end{array}$ \\
\hline 胥 & $\overrightarrow{0}$ & 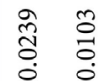 \\
\hline$\stackrel{\circ}{\square}$ & 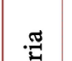 & \\
\hline 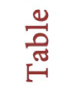 & 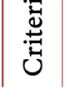 & $P^{+} \quad>^{\prime}$ \\
\hline
\end{tabular}


Table 17. Relative closeness and final ranking table.

\begin{tabular}{cccc}
\hline $\mathrm{Si}+$ & $\mathrm{Si}-$ & $\mathrm{Ci}$ & Rank \\
\hline $\mathbf{0 . 0 2 6 9}$ & 0.0372 & 0.5801 & $\mathbf{1}$ \\
$\mathbf{0 . 0 3 2 5}$ & 0.0252 & 0.4372 & $\mathbf{3}$ \\
$\mathbf{0 . 0 3 6 4}$ & 0.0272 & 0.4272 & $\mathbf{4}$ \\
$\mathbf{0 . 0 2 6 0}$ & 0.0343 & 0.5686 & $\mathbf{2}$ \\
$\mathbf{0 . 0 3 1 0}$ & 0.0215 & 0.4095 & $\mathbf{5}$ \\
$\mathbf{0 . 0 3 9 9}$ & 0.0209 & 0.3440 & $\mathbf{6}$ \\
\hline
\end{tabular}

values are used to give the best and worst alternatives for each criterion.

The values in Table 15, were calculated using the formula 8 , the weights were determined using the data ranking and weights awarded by the experts according to their practical experience.

\section{Conclusion}

The results obtained agree with the TOPSIS ranking technique. Alternative 1 is ranked at first position: this is the best alternative available if we consider all of the 23 criteria weighted by the experts. The remaining alternatives are ranked accordingly considering the rest of criteria the best suitable for those materials.

\section{Acknowledgements}

M.R.M. gathered all the data and ran the analysis in the presented format. V.P. cross-checked all the information and validated the results with his experience in Information Systems.

\section{Funding}

This research received no external funding, only the resources provided by Curtin University, Perth, Western Australia.

\section{Conflicts of Interest}

The authors declare no conflicts of interest.

\section{References}

[1] Dulaimi, M.F., Ling, F.Y. and Bajracharya, A. (2003) Organizational Motivation and Inter-Organizational Interaction in Construction Innovation in Singapore. Construction Management and Economics, 21, 307-318. https://doi.org/10.1080/0144619032000056144

[2] Black, C., Akintoye, A. and Fitzgerald, E. (2000) An Analysis of Success Factors and Benefits of Partnering in Construction. International Journal of Project Management, 18, 423-434. https://doi.org/10.1016/S0263-7863(99)00046-0

[3] Chinyio, E.A. and Olomolaiye, P.O. (1999) A Needs Based Methodology for Classifying Construction Clients and Selecting Contractors-A Rejoinder. Construction Management \& Economics, 17, 413-417. https://doi.org/10.1080/014461999371330 
[4] Gliem, J.A. and Gliem, R.R. (2003) Calculating, Interpreting, and Reporting Cronbach's Alpha Reliability Coefficient for Likert-Type Scales. Midwest Research to Practice Conference in Adult, Continuing, and Community Education, Ohio State University, 82-88.

[5] Marshall, B., Cardon, P., Poddar, A. and Fontenot, R. (2013) Does Sample Size Matter in Qualitative Research? A Review of Qualitative Interviews in IS Research. Journal of Computer Information Systems, 54, 11-22. https://doi.org/10.1080/08874417.2013.11645667

[6] Francis, J.J., Johnston, M., Robertson, C., Glidewell, L., Entwistle, V., Eccles, M.P., et al. (2010) What Is an Adequate Sample Size? Operationalising Data Saturation for Theory-Based Interview Studies. Psychology and Health, 25, 1229-1245. https://doi.org/10.1080/08870440903194015

[7] Munn, P. and Drever, E. (1990) Using Questionnaires in Small-Scale Research. A Teachers' Guide, ERIC.

[8] Mason, M. (2010) Sample Size and Saturation in PhD Studies Using Qualitative Interviews. Forum Qualitative Sozialforschung/Forum: Qualitative Social Research.

[9] Wang, L., Shen, W., Xie, H., Neelamkavil, J. and Pardasani, A. (2002) Collaborative Conceptual Design-State of the Art and Future Trends. Computer-Aided Design, 34, 981-996. https://doi.org/10.1016/S0010-4485(01)00157-9

[10] Rao, P. and Holt, D. (2005) Do Green Supply Chains Lead to Competitiveness and Economic Performance? International Journal of Operations \& Production Management, 25, 898-916. https://doi.org/10.1108/01443570510613956

[11] Ding, G.K. (2008) Sustainable Construction-The Role of Environmental Assessment Tools. Journal of Environmental Management, 86, 451-164. https://doi.org/10.1016/j.jenvman.2006.12.025

[12] Tan, Y., Shen, L. and Yao, H. (2011) Sustainable Construction Practice and Contractors' Competitiveness: A Preliminary Study. Habitat International, 35, 225-230. https://doi.org/10.1016/j.habitatint.2010.09.008

[13] Bribián, I.Z., Capilla, A.V. and Usón, A.A. (2011) Life Cycle Assessment of Building Materials: Comparative Analysis of Energy and Environmental Impacts and Evaluation of the Eco-Efficiency Improvement Potential. Building and Environment, 46, 1133-1140. https://doi.org/10.1016/j.buildenv.2010.12.002

[14] Dair, C.M. and Williams, K. (2006) Sustainable Land Reuse: The Influence of Different Stakeholders in Achieving Sustainable Brownfield Developments in England. Environment and Planning A, 38, 1345-1366. https://doi.org/10.1068/a37370

[15] Xu, Z. and Yager, R.R. (2006) Some Geometric Aggregation Operators Based on Intuitionistic Fuzzy Sets. International Journal of General Systems, 35, 417-433. https://doi.org/10.1080/03081070600574353

[16] Omar, M.N. and Fayek, A.R. (2016) A TOPSIS-Based Approach for Prioritized Aggregation in Multi-Criteria Decision-Making Problems. Journal of Multi-Criteria Decision Analysis, 23, 197-209. https://doi.org/10.1002/mcda.1561

[17] Zhao, X., Lin, R. and Wei, G. (2013) Fuzzy Prioritized Operators and Their Application to Multiple Attribute Group Decision Making. Applied Mathematical Modelling, 37, 4759-4770. https://doi.org/10.1016/j.apm.2012.09.048

[18] Yager, R.R., Gumrah, G. and Reformat, M.Z. (2011) Using a Web Personal Evaluation Tool-PET for Lexicographic Multi-Criteria Service Selection. Knowledge-Based Systems, 24, 929-942. https://doi.org/10.1016/j.knosys.2011.02.004

[19] Chen, L. and Xu, Z. (2014) A Prioritized Aggregation Operator Based on the OWA 
Operator and Prioritized Measure. Journal of Intelligent \& Fuzzy Systems, 27, 1297-1307. https://doi.org/10.3233/IFS-131098

[20] Chu, T.-C. (2002) Facility Location Selection Using Fuzzy TOPSIS under Group Decisions. International Journal of Uncertainty, Fuzziness and Knowledge-Based Systems, 10, 687-701. https://doi.org/10.1142/S0218488502001739

[21] Lootsma, F.A. (2000) Distributed Multi-Criteria Decision Making and the Role of the Participants in the Process. Journal of Multi-Criteria Decision Analysis, 9, 45-55. https://doi.org/10.1002/1099-1360(200001/05)9:1/3<45::AID-MCDA266>3.0.CO;2L

[22] Yager, R.R. (2009) Prioritized OWA Aggregation. Fuzzy Optimization and Decision Making, 8, 245-262. https://doi.org/10.1007/s10700-009-9063-4

[23] Bisdorff, R., Meyer, P. and Veneziano, T. (2014) Elicitation of Criteria Weights Maximising the Stability of Pairwise Outranking Statements. Journal of Multi-Criteria Decision Analysis, 21, 113-124. https://doi.org/10.1002/mcda.1496

[24] Çalışkan, H., Kurşuncu, B., Kurbanoğlu, C. and Güven, Ş.Y. (2013) Material Selection for the Tool Holder Working under Hard Milling Conditions Using Different Multi Criteria Decision Making Methods. Materials \& Design, 45, 473-479. https://doi.org/10.1016/j.matdes.2012.09.042

[25] Yoon, K. (1980) Systems Selection by Multiple Attribute Decision Making. PhD Thesis, Kansas State University, Manhattan (KS).

[26] Hwang, B.G. and Tan, J.S. (2012) Green Building Project Management: Obstacles and Solutions for Sustainable Development. Sustainable Development, 20, 335-349. https://doi.org/10.1002/sd.492

[27] Tzeng, G.-H., Lin, C.-W. and Opricovic, S. (2005) Multi-Criteria Analysis of Alternative-Fuel Buses for Public Transportation. Energy Policy, 33, 1373-1383.

https://doi.org/10.1016/j.enpol.2003.12.014

[28] Shanian, A. and Savadogo, O. (2006) TOPSIS Multiple-Criteria Decision Support Analysis for Material Selection of Metallic Bipolar Plates for Polymer Electrolyte Fuel Cell. Journal of Power Sources, 159, 1095-1104. https://doi.org/10.1016/j.jpowsour.2005.12.092

[29] Sharma, P.K., Aggarwal, A. and Gupta, R. (1993) An Expert System for Aid in Material Selection Process. Proceedings of the Engineering Management Society Conference on Managing Projects in a Borderless World, New Delhi, 17-18 December 1993, 27-31.

[30] Chatterjee, P., Athawale, V.M. and Chakraborty, S. (2010) Selection of Industrial Robots Using Compromise Ranking and Outranking Methods. Robotics and Computer-Integrated Manufacturing, 26, 483-489. https://doi.org/10.1016/j.rcim.2010.03.007 